\title{
The improvement of quality management system in a porcelain factory
}

\author{
Adina Sârb ${ }^{1, *}$, Ioana Glevitzky ${ }^{1}$, Liliana Itul $^{2}$, and Maria Popa $^{3}$ \\ ${ }^{1}$ Doctoral School, Faculty of Engineering, "Lucian Blaga" University of Sibiu, Romania \\ ${ }^{2}$ Quality Department, S.C. Apulum S.A., Alba Iulia, Romania \\ ${ }^{3}$ The Business Administration and Marketing Department, Faculty of Economic Science, "1 \\ Decembrie 1918" University of Alba Iulia, Romania
}

\begin{abstract}
According to SR EN ISO 9000:2015, quality management system can be considered "a set of Policies, Procedures, Processes and resources used to achieve the organization objectives and desired results, by manages the interacting processes, resources required and inter-related parts of the business". The requirements of a quality management system that need to be implemented by companies in order to produce high quality products and to achieve continual improvement are described in ISO 9001. The aim of this research is to improve the quality management system implemented in a porcelain factory, named S.C. APULUM S.A. The implementation of ISO 9001:2015 in the organization involves monitoring process performance through different performance indicators. The first performance indicator highlights the situation regarding the quality of the products manufactured in a certain period and the second one emphasizes the most common defects of one of the products fabricated in the organization. Hence, identified nonconformities are analyzed using 8D method in order to identify the root-cause and to remove it. The results show that different solutions were identified and implemented in order to enhance the quality management system in the company considered.
\end{abstract}

\section{Introduction}

Due to an increasingly complex and challenging competitive environment, many organizations have adopted Quality Management Systems (QMS) like the ISO 9001: International Standard Series or Business Excellence Models (BEM), such as the European Foundation for Quality Management (EFQM) model [1].

A QMS is an integrated set of activities to establish and control work processes, manage resources, conduct evaluations and continually improve [2]. A QMS covers a broader range of activities than quality control (QC - tool used to prevent defects, shortcomings and incompatibilities, and to maintain an appropriate level of compliance while retaining an optimal level of costs and quality assurance (QA - tool used to ensure that quality requirements are met [3] by including both technical and management requirements [2].

\footnotetext{
* Corresponding author: sarb.adina92@yahoo.com
} 
The ISO-based QMS is an internationally recognized standard that can be implemented by any organization, whether small or large [4]; hence, the first edition of the ISO 9000 series - ISO 9001 QMS (appeared in 1987) has been implemented by more than one million organizations of all activity sectors in 187 countries worldwide $[5,6]$.

There is a general concern regarding the contribution of ISO 9001 towards quality improvement and customer satisfaction, despite the exponential increase in the number of certified companies. There are many reasons provided by companies when justifying their decision to obtain ISO 9001 certificate. The requirement of customers and the access to new markets has traditionally been the alleged reasons. But the arguments raised by companies already certified, when recommending the certification to other companies, regardless of what have been their own reasons to certify, identify the benefits of all types, derived from obtaining certification [7].

This paper approach a study case which contains in the first stage the monitoring of two performance indicators of the production process deployed in S.C. APULUM S.A. In the second stage, $8 \mathrm{D}$ methodology will be applied in order to identify the root cause of one of the problems resulting from the first stage of the research and in the third stage different solutions will be established and implemented to improve the quality management system in the porcelain factory.

\section{Literature review}

ISO 9001:2015 is the latest version of the ISO 9001 standard and it was released in 2015. The guidelines contained in this new revision are based on the results of an extensive survey, and consider the increasing diversity of ISO QMS users, new development in knowledge and technologies, broader interest of users in matters related to quality, and changes in the industry [4].

ISO 9001:2015 contains the following 10 clauses: 1. Scope, 2. Normative References, 3. Terms and Definitions, 4. Context of the Organization, 5. Leadership, 6. Planning, 7. Support, 8. Operation, 9. Performance Evaluation and 10. Improvement [4].

The purpose of the ISO 9001 standard is to improve the performance of the organization, as well as ensure the customers' satisfaction [8]. Thus, understanding the purpose of the ISO 9001 is an important preliminary step in the process of implementation to achieve the benefits derived from certification [7]. The most important internal benefits resulting from the certification of a QMS based on ISO 9001 are: improvement in the organizational culture, improvement in the working process definition, higher confidence in quality in the organization, increased involvement of people, operational management improvements (productivity, efficiency and cost reductions), improved process and product quality (product defect rate decrease, elimination of non-value added work), short delivery time, organizational effectiveness (internal control, training and communication), improved system documentation, work environment improvement. Among the most significant external benefits are: better customer service (increased customer satisfaction and complaints reduction, customer communication improvements), fewer complaints with suppliers (less inspection, improved inbound quality), fewer customer audits, marketing advantages (improved image, sales and market share), competitive advantage improvement [6-8].

In 2015 editions, ISO has also updated the quality management principles (QMPs) that support ISO 9000 and ISO 9001 QMS [6]. Now, there are seven QMPs, which are illustrated in Figure 1. These principles are not listed in priority order. The relative importance of each principle will vary from organization to organization and can be expected to change over time [9]. Also, presented QMPs are briefly described in Table 1 $[6]$. 


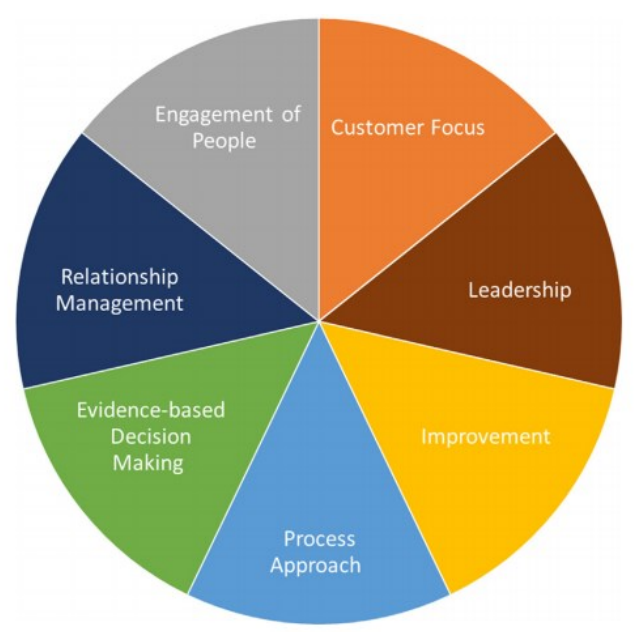

Fig. 1. Quality management principles [6]

Table 1. Description of QMPs [6]

\begin{tabular}{|c|c|}
\hline QMPs & Statement \\
\hline 1. Customer focus & $\begin{array}{l}\text { The primary focus of quality management is to meet } \\
\text { customer requirements and to strive to exceed } \\
\text { customer expectations. }\end{array}$ \\
\hline 2. $\quad$ Leadership & $\begin{array}{l}\text { Leaders at all levels establish unity of purpose and } \\
\text { direction and create conditions in which people are } \\
\text { engaged in achieving the organization's quality } \\
\text { objectives. }\end{array}$ \\
\hline $\begin{array}{l}\text { 3. Engagement of } \\
\text { people }\end{array}$ & $\begin{array}{l}\text { Competent, empowered and engaged people at all } \\
\text { levels throughout the organization are essential to } \\
\text { enhance its capability to create and deliver value } \\
\text { (involvement of people in ISO 9000:2005 and ISO } \\
9001: 2008) \text {. }\end{array}$ \\
\hline 4. Process approach & $\begin{array}{l}\text { Consistent and predictable results are achieved more } \\
\text { effectively and efficiently when activities are } \\
\text { understood and managed as interrelated processes that } \\
\text { function as a coherent system (this principles } \\
\text { encompasses the systems approach to management of } \\
\text { ISO 9000:2005 and ISO 9001:2008 editions). }\end{array}$ \\
\hline 5. Improvement & $\begin{array}{l}\text { Successful organizations have an ongoing focus on } \\
\text { improvement (continual improvement in ISO } \\
\text { 9000:2005 and ISO 9001:2008 editions). }\end{array}$ \\
\hline $\begin{array}{l}\text { Evidence-based } \\
\text { decision-making }\end{array}$ & $\begin{array}{l}\text { Decision based on the analysis and evaluation of data } \\
\text { and information are more likely to produce desired } \\
\text { results (factual approach to decision-making in ISO } \\
\text { 9000:2005 and ISO 9001:2008 editions). }\end{array}$ \\
\hline $\begin{array}{l}\text { 7. Relationship } \\
\text { management }\end{array}$ & $\begin{array}{l}\text { For sustained success, an organization manages its } \\
\text { relationships with interested parties, such as suppliers } \\
\text { (mutually beneficial supplier relationships in ISO } \\
\text { 9000:2005 and ISO 9001:2008 editions). }\end{array}$ \\
\hline
\end{tabular}




\section{Research method}

Eight Disciplines of Problem Solving (8D) method (also called G8D, Global 8D, TOPS 8D) was used in order to realize the case study of the paper. It is a complex tool for solving problems of significant scale which are hard for individuals to solve and involves solutions which require extra resources. In general, though, $8 \mathrm{D}$ is considered as a highly effective tool for searching for the root causes of nonconformities and for the implementation of corrective actions. The reason why this method has received respect and it is recognized by the world's best vehicle makers is the fact that it conducts a thorough study of the system in which the nonconformity occurred to prevent the reoccurrence of similar events in the future. The original $8 \mathrm{D}$ process was pioneered by Ford Motor Company and it was called TOPS (Team Oriented Problem Solving) [10].

This method involves teams working together in order to solve problems, using a structured 8 steps (also, called disciplines) approach to help focus on facts, instead of opinions [11].

When properly applied, 8D method can lead to the following benefits:

- Improved team oriented problem solving skills rather than reliance on the individual;

- Increased familiarity with a structure for problem solving;

- Creation and expansion of a database of past failures and lessons learned to prevent problems in the future;

- Better understanding of how to use basic statistical tool required for problem solving;

- Improved effectiveness and efficiency at problem solving;

- A practical understanding of Root Cause Analysis (RCA);

- Problem solving effort may be adopted into the processes and methods of the organization;

- Improved skills for implementing corrective action;

- Better ability to identify necessary systemic changes and subsequent inputs for change;

- More candid and open communication in problem solving discussion, increasing effectiveness;

- An improvement in management's understanding of problems and problem resolution [12].

In order to enhance the quality management system in the factory considered in the case study the steps illustrated in Figure 2 were followed. 


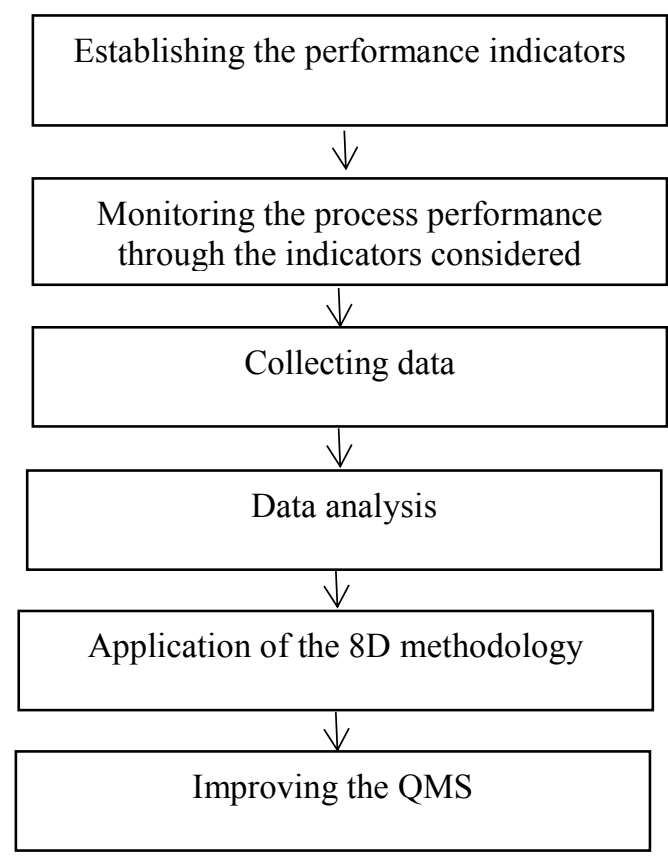

Fig. 2. Steps followed in order to realize the case study

\section{Case study}

The objective of this paper is to improve the quality management system in the company S.C. APULUM S.A. by monitoring different performance indicators.

The company considered in the case study was founded in 1970 in the city of Alba Iulia. It is the largest porcelain manufacturer in Romania and also in South-Est Europe, with a variety of production: household and HoReCa articles on porcelain, decorative objects, frills.

The porcelain factory implemented, certified and maintained up to now a QMS since 1998 according to ISO 9001:1994. In 2017, the company was recertified in accordance to ISO 9001:2008 and last year, in 2018 took place the surveillance audit with transition on ISO 9001:2015 [13].

The first performance indicator taken into account is the evolution of the products manufactured within the company. This indicator refers to the framing of the products in five categories. The results obtained in 2018 are illustrated in Figure 3. 


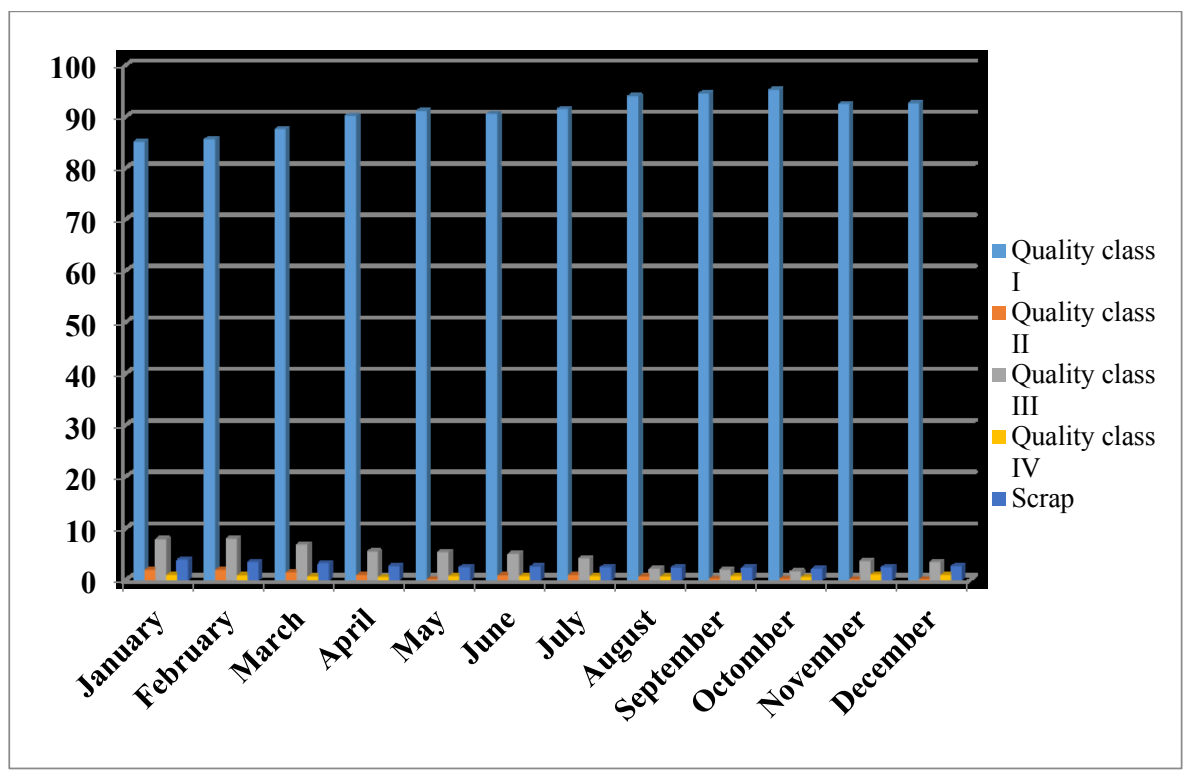

Fig. 3. The situation regarding the products manufactured in 2018

It is observed that the products are divided into four quality classes, respectively I, II, III and IV. The products which do not fit into any of the mentioned quality classes are considered scrap.

Regarding the quality class I it is noticed that from the beginning of the year until May there was a monthly increase of its percentage, in June there was a slight decrease followed by another increase between July and Octomber. In the last two months there was a reduction of $2.7 \%$, respectively $2.6 \%$.

As respect to scrap, between January and May there was a fall of its percentage. In June there was a growth then in the next four months there was a decrease. In November and December there was an increase of scrap's percentage.

In the quality classes II, III and IV throughout 2018 there were several variations of the percentage.

Classification of the products by quality classes is based on the defects characteristic of porcelain products, so the second performance indicator supposes to reduce the number of defects of the products in order to improve the quality. In this paper, due to the large number of products, one of the most problematic products in terms of defects was chosen, it is named Serving Plate.

In 2018 were carried out 15 surveys for the product taken into account. These surveys involve classifying the product into quality classes and identifying characteristic defects. The situation resulting from the surveys conducted regarding the product classification by quality classes is highlighted in Figure 4. 


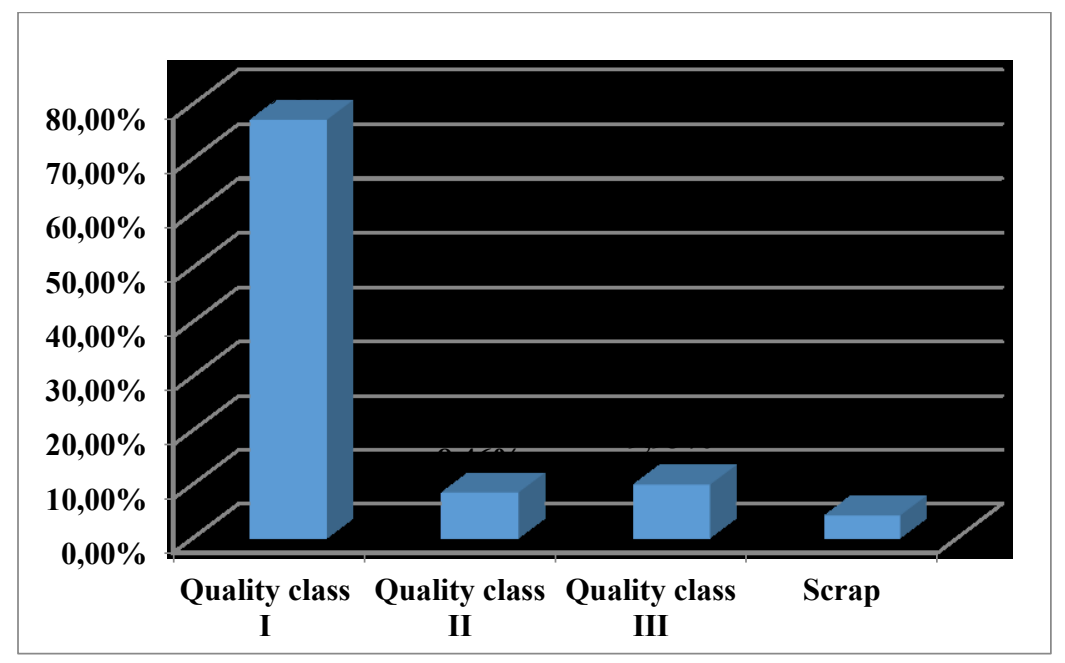

Fig. 4. Classification of the product considered into quality classes (resulting from the surveys)

In this figure, we can observe that the assortment chosen in this paper is divided in three of the four quality classes, respectively quality class I, quality class II and quality class III. Products which do not fit any quality class are considered scrap.

Because the surveys were conducted on the samples, errors occurred on the data obtained. Therefore, in the final sorting, piece by piece, were obtained another results illustrated in Figure 5.

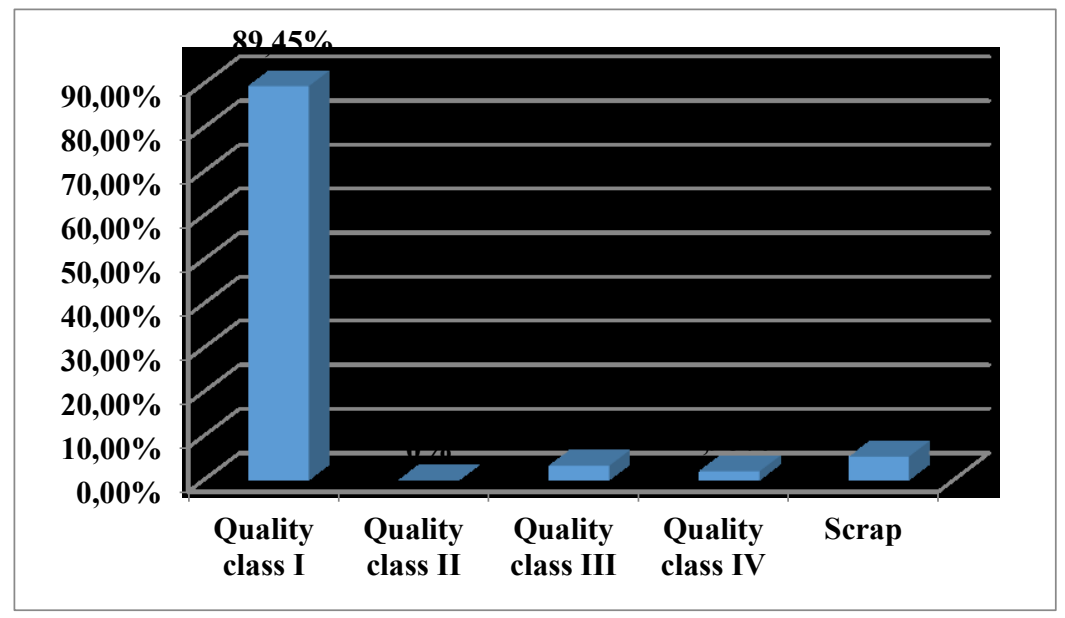

Fig. 5. Classification of the product considered into quality classes (resulting from the final sorting)

This figure shows that the product considered is framed in all categories identified in the company, meaning quality class I, quality class II, quality class III, quality class IV and scrap.

It is observable that the percentage of quality class I obtained from the final sorting is higher than the percentage resulted from the surveys with $12,82 \%$. Also, diferences occur in the other categories. For example, regarding the scrap in Figure 5 the percentage value is 5.30 while in Figure 4 the percentage value is 4.21.

As it is mentioned above, the classification of the products by quality classes is made according to the defects and customer requirements. Figure 6 shows the situation regarding the defects found at the product considered resulted from the analysis of the surveys. 


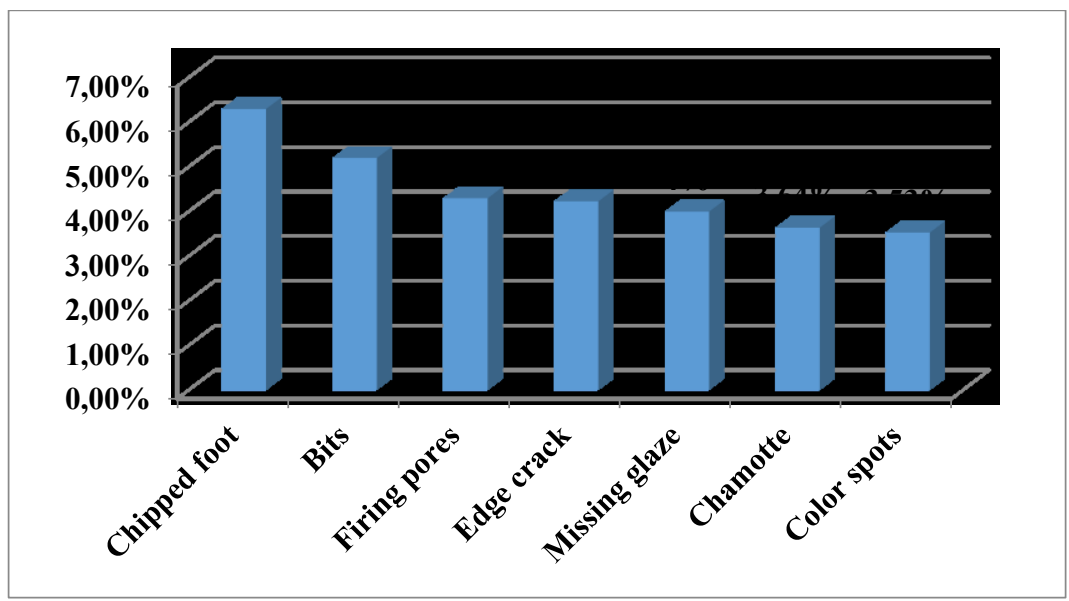

Fig. 6. Recorded defects of the ceramic product - Serving Plate

In this situation, 7 of the 34 defects specific to ceramic products identified in the company are found. The defect that appears more often is chipped foot with $6.30 \%$ and the most rarely encountered defect is color spots with 3.53\%. Products with such defects can be classified into different quality classes, but products with edge cracks are classified as scrap, with few exceptions in some cases when cracks are very small and closed. So, in this case, edge cracks are considered one of the critic defects, thus $8 \mathrm{D}$ method is applied in order to identify the root cause of the cracks and to remove it. As mentioned in Chapter 3, this method is based on 8 Disciplines. The effectiveness of this method is to cover each disciplines. Therefore, each discipline will be treated separately.

Discipline 0: Prepare for $8 D$ process

The team will be formed with members with different specializations within the company. The time allocated for applying the method is 2 weeks. Also, all necessary resources (financial, material, human, time) will be available in order to perform in optimal conditions the process.

Discipline 1: Select the team

In concrete terms, the team consists of the following members:

- Production coordinator: C.A.

- Forming responsible: B.P.

- $\quad$ Firing responsible: B. S.

- Quality manager: I. L.

- Tehnical-laboratory representative: C. A.

- Technical-laboratory representative: S. A.

Discipline 2: Description of the problem

In the present case, the problem is represented by the presence of edge cracks at Serving Plate. For the purpose of collecting information regarding the presence of cracks on the product considered, 15 surveys were carried out and analyzed. The results are shown in Table 2. 
Table 2. The results of the surveys regarding the edge cracks

\begin{tabular}{|c|c|c|}
\hline No. & Edge cracks[\%] & Scrap [\%] \\
\hline 1. & 7 & 7 \\
\hline 2. & 1 & 1 \\
\hline 3. & 4 & 4 \\
\hline 4. & 3 & 3 \\
\hline 5. & 7 & 11 \\
\hline 6. & 13 & 11 \\
\hline 7. & - & 1 \\
\hline 8. & 1 & 1 \\
\hline 9. & 2 & 2 \\
\hline 10. & 4 & 4 \\
\hline 11. & 7 & 7 \\
\hline 12. & 4 & 5 \\
\hline 13. & 1 & 1 \\
\hline 14. & - & - \\
\hline 15. & 1 & 1 \\
\hline Average [\%] & $\mathbf{4 . 2 3}$ & $\mathbf{4 . 2 1}$ \\
\hline
\end{tabular}

In this table it is noticed that edge cracks appear in 13 of the 15 surveys carried out. Also, in $78 \%$ cases the percentage of cracks is identical with the percentage of scrap, which means that this defect is the main cause of the scrap. In one of the surveys the percentage of cracks is higher than the percentage of scrap; this thing can be explained by the fact that some of the cracks were very small and closed and the products were classified in a quality class. Also, in the same table it is presented the average of cracks in 2018, which is higher with $0.2 \%$ than the average of scrap.

Discipline 3: Implementing a temporary solution

Until the problem is solved, it is necessary to block the raw materials used to produce this product. Also, existing products in the stock will be carefully sorted in order to send to the customers only products that meet their requirements.

Discipline 4: Identifying and eliminating the root cause

Ishikawa diagram is used in order to identify the root cause of the problem. It is a diagram of cause and effect which allows disclosure and collection of factors influencing the investigated process or event. Creating this diagram is based on the fact that every event has an infinite number of causative factors. There are few really important and sharply influencing events (effects). The significance of the diagram in the area of quality lies in its function for improving a quality system. The diagram is shaped like a fishbone and the main axis is quality management. The backbone has bones individually placed diagonally and these bones represent axes of main components contributing towards the final quality of the company's products and services. These components - areas - must be harmonized and their interactions provides optimum synergy effect for the company [14]. The application of the Ishikawa diagram in order to identify the cause of the cracks at the edge of the product considered is shown in Figure 7. 


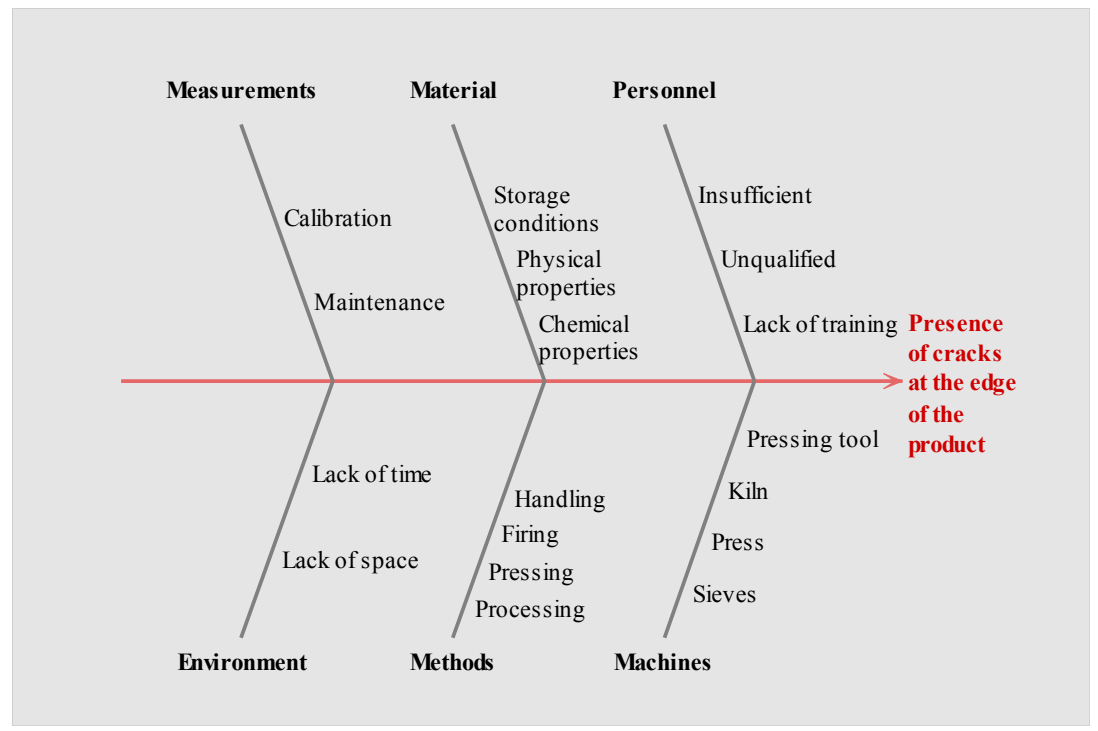

Fig. 7. Ishikawa Diagram used to identify the root cause of cracks

After analyzing the Ishikawa diagram, several solutions have been identified, such as:

- $\quad$ Selecting the right press mass;

- Proper storage of the raw material (application of the plastic foil to the bags of raw materials to preserve their characteristics);

- Adequate setting of the press parameters;

- Modification of the pressing tool according to the type of press;

- Supplementation with trolleys for the storage of the products in the raw stage;

- Keeping the products for a certain period before their first firing in order to remove their own tensions;

- $\quad$ Selecting the optimum firing parameters;

- Training the employees involved in order to properly handle the products.

Discipline 5: Verifying the solution

All the solutions identified at Discipline 4 were tested. So, the storage of raw materials was done in optimal conditions; the press parameters and the pressing tool were modified; trolleys for product storage were purchased; the products were kept for 24 hours before the firing in order to eliminate the tensions. Also, mass with another characteristics were used and the operating parameters of the firing kilns I and II have been modified. In the same time took place an upgrade of the product documentation and a training of the employees involved.

\section{Discipline 6: Implementing the permanent solution}

The solutions identified have been implemented for one month. During this time several product surveys were conducted. The analysis of the surveys shows an improvement regarding the presence of cracks at the edge at Serving Plate.

Discipline 7: Preventing the recurrence of the problem

To prevent the occurrence of the problem a special attention is paid in order to maintain and monitor the parameters listed in the product documentation. Also, all involved employees were trained in agreement with the changes.

Discipline 8: Celebrating the team's success

Celebrating the team's success consists in recognizing the merits of each member of the team in the process of solving the problem. 


\section{Conclusion}

According to ISO 9001:2015 one of the company's goals is to improve the quality management system implemented in the organization. In this regard two of the performance indicators used to monitor and to improve the quality in the company considered were approached in this paper.

The first performance indicator is used in order to identify the current level of quality of the products manufactured in S.C. APULUM S.A. It is observed that during 2018 there were several variations regarding the classification of the products on different categories. Oscillations appearing throughout the year, both in terms of quality and scrap are influenced by the structure of the planned articles, which depends on customer orders, which have specific quality standards. Also, starting with the second half of the year, there has been a change in the management strategy, which led to an increase in the quality of the products manufactured within the company, simultaneously with the reduction of the scrap.

The second performance indicator assume to identify defects characteristic of porcelain products and to reduce them by using different quality tools, which contributes to the improvement of the quality management system in the company. In this regard, one of the products of the company was chosen and one of the critic defects for customers was analyzed. Following the application of $8 \mathrm{D}$ method, various solutions for the reduction of the edge cracks were identified and implemented, which has led to the improvement of the product quality in a short time.

\section{References}

1. L. Fonseca, V. Lima, M. Silva, IJQR, 9, 606 (2015)

2. L. Fonseca, V. Lima, M. Silva, IJQR, 9, 606 (2015)

3. R. B. Carey, Clin. Microbiol. Newsl., 40, 184 (2018)

4. H. Gołas, CCIS, 435, 520 (2014)

5. C-K. Chen, K. Anchecta, Y-D. Lee, J. J. Dahlgaard, MPER, 7, 66 - 72 (2016)

6. B. Urban, M. Toga, IJQR, 11, 754 (2017)

7. L. Fonseca, P. Domingues, IJQR, 11, 149 - 152 (2016)

8. G. Santos, B. Costa, A. Leal, IJEST, 6, 1 - 2 (2016)

9. T.V. Nunhes, L.C.F. Motta Barbosa, O.J. Oliveira, J. Clean. Prod., 142, 3226 - 3228 (2017)

10. R. Refaat, I.M. El-Henawy, Cogn. Syst. Res., In Press, 2 (2018)

11. A. Chlpeková, P. Večeřa, Y. Šurinová, Int. J. Eng. Bus. Manag., 6, 1 - 2 (2014)

12. C. A. Riesenberger, S.D. Sousa, Proceedings of the WCE, 3, 1 (2010)

13. Quality-One International [online] Available at https://quality-one.com/8d/ [accessed 07.02.2019]

14. A. Sârb, L. Itul, M. Popa, Proceedings of EMEB, 6, 223 (2018)

15. L. Simanova, P. Gejdos, Procedia Econ. Financ., 34, 279 (2015) 